\begin{tabular}{ll|l} 
Case Reports in & \multicolumn{2}{c}{ Case Rep Gastroenterol 2013;7:97-105 } \\
\cline { 2 - 3 } Gastroenterology & $\begin{array}{l}\text { DOI: 10.1159/000350192 } \\
\text { Published online: March 7, 2013 }\end{array}$ & $\begin{array}{l}\text { ○ 2013 S. Karger AG, Basel } \\
1662-0631 / 13 / 0071-0097 \$ 38.00 / 0 \\
\text { www.karger.com/crg }\end{array}$ \\
\hline & $\begin{array}{l}\text { This is an Open Access article licensed under the terms of the Creative Commons Attribution- } \\
\text { NonCommercial-NoDerivs 3.0 License (www.karger.com/OA-license), applicable to the } \\
\text { online version of the article only. Distribution for non-commercial purposes only. }\end{array}$
\end{tabular}

\title{
Treatment of Esophageal Variceal Hemorrhage with Self-Expanding Metal Stents as a Rescue Maneuver in a Swiss Multicentric Cohort
}

\author{
Fabienne C. Fierz ${ }^{\mathrm{a}} \quad$ Walter Kistler $^{\mathrm{a}} \quad$ Volker Stenz $^{\mathrm{b}} \quad$ Christoph Gubler $^{\mathrm{c}}$ \\ ${ }^{a}$ Spital Davos, Klinik für Innere Medizin, Davos, ${ }^{b}$ Kantonsspital Münsterlingen, Klinik für \\ Innere Medizin, Münsterlingen, and ' Universitätsspital Zürich, Klinik für Gastroenterologie \\ und Hepatologie, Zürich, Switzerland
}

\section{Key Words}

Self-expanding metal stents $\cdot$ Esophageal varices $\cdot$ Balloon tamponade $\cdot$ Refractory bleeding

\begin{abstract}
Acute esophageal variceal bleeding in patients with portal hypertension remains a complication with a high mortality today. In cases refractory to standard therapy including endoscopic band ligation and pharmacological therapy, traditionally balloon tamponade has been used as salvage therapy. However, these techniques show several important limitations. Selfexpanding metal stents (SEMS) have been proposed as an alternative rescue treatment. The use of variceal stenting in 7 patients with a total of 9 bleeding episodes in three different Swiss hospitals is demonstrated. While immediate bleeding control is achieved in a high percentage of cases, the 5-day and 6-week mortality rate remain high. Mortality is strongly influenced by the severity of the underlying liver disease. Accordingly, our data represent a high-risk patient collective. Thanks to their safety and easy handling, SEMS are an interesting alternative to balloon tamponade as a bridging intervention to definitive therapy including the pre-hospital setting.
\end{abstract}

\section{Introduction}

Today's standard therapy for acute esophageal variceal hemorrhage includes the combination of vasoactive drugs, endoscopic band ligation [1] and short-term administration of antibiotics. Furthermore, Garcia-Pagán et al. [2] have shown in 2010 that early transjugular intrahepatic portosystemic shunt (TIPS) placement within $72 \mathrm{~h}$ in patients at high risk of 
treatment failure significantly reduces mortality. Despite the various treatment approaches, the 6-week mortality rate linked to variceal bleeding still ranges from 15 to $20 \%$ depending on underlying severity of the liver disease [3-5]. As a late example, the mortality within 6 weeks of follow-up among 162 patients in Spain who received emergency band ligation during an observation period of 9 years was $16 \%$. It is important to point out that thereby mortality depends strongly on the risk subgroups of the patients [6].

First approaches of using direct compression to treat bleeding esophageal varices were described by Westphal in 1930. In 1950, the Sengstaken-Blakemore tube was developed. As reported by Panés et al. [7], balloon tamponade remained the first-line therapy in acute variceal hemorrhage in the 1980s. While the Sengstaken-Blakemore tube was being used in the outweighing cases of esophageal varices, the Linton-Nachlass tube has been preferred for the compression of gastric varices.

The success rates of balloon tamponade concerning short-term bleeding control vary from 50 up to $91.5 \%$ [7-9]. The main complications associated with balloon tamponade include aspiration pneumonia in unventilated patients, large esophageal ulcers, esophageal tears and airway obstruction [9]. Rebleeding was observed in about half of the patients when the balloon was deflated [7]. In a prospective multicenter study conducted by Sorbi et al. in 2003 [10], balloon tamponade was used in 5.5\% of patients with a first bleeding episode and in $17.4 \%$ of patients with a recurrent bleeding within 2 weeks. Latest consensus guidelines suggest that balloon tamponade does still play a role today, but should only be used in massive uncontrolled bleeding and only as a bridging measure for a maximum of $24 \mathrm{~h}$ until definitive therapy can be initiated [11].

Since 2003, a new rescue treatment modality has been introduced. While traditionally self-expanding metal stents (SEMS) have been used in oncology with good success in stenosing esophageal cancer [12], Hubmann et al. [13] have developed a fully covered SEMS to be used as an alternative to balloon tamponade in acute refractory variceal hemorrhage. Four different studies so far, the largest series including 34 patients, have shown encouraging results in terms of immediate bleeding control rates and low proportion of complications [13-16]. These data suggest that covered SEMS may be an option in refractory esophageal bleeding [11] and may replace balloon tamponade as a salvage technique in the future. In the case of bleeding gastric varices, Linton tubes will still be needed. Generally, experience and evidence regarding this method are not yet profound. Here we have collected a total of 9 cases of stent employment in 7 patients in three different Swiss hospitals in an emergency setting in acute variceal bleeding.

\section{Case Reports}

Our collective covers a total of 9 variceal bleeding events in 7 cirrhotic patients as summarized in table 1 . The cases are derived from three different Swiss hospital facilities (one primary, one secondary and one tertiary referral center) in the time period from October 2010 to October 2011. In the majority of cases, failure of standard approaches including band ligation, sclerotherapy and even emergency TIPS to stop hemorrhage led to the insertion of an SX-ELLA Stent Danis (ELLA-CS, Hradec-Kralove, Czech Republic). The stent and its delivery system are depicted in figure 1 and the insertion procedure is explained in figure 2. In 3/9 cases, insertion of the stent was performed as first-line emergency treatment besides standard pharmacological therapy. Stenting led to immediate bleeding control (at time of endoscopy) in 89\% (8/9 cases). The only case with missing hemorrhage control was due to unsuccessful stent deployment. One patient received an additional Linton tube to 
compress gastric fundus varices (case 5 in table 1). Duodenal varices in case 1 in table 1 were treated by histoacryl injection simultaneously to stenting of esophageal varices. In $44 \%$ (4/9) of the cases, the patient survived the acute bleeding episode for 5 days as defined by the Baveno V consensus guidelines [11]. After 6 weeks, only $22 \%(2 / 9)$ of the patients were still alive. Cases $1 \mathrm{a}+\mathrm{b}$ and 2 have been chosen exemplarily to be described in detail below. One additionally inserted SX-ELLA Stent Danis used in prophylactic intention after endoscopic mucosectomy in the distal esophagus with large varices was not included in this cohort. Anyhow, this case was uneventful considering insertion, removal and long-term follow-up.

\section{Case $1 a+b$}

The 56-year-old patient with known ethyl-toxic liver cirrhosis was admitted to the emergency room after 1 day of ongoing hematochezia. She presented with an initial hemoglobin level of $25 \mathrm{~g} / \mathrm{l}$. At emergency endoscopy, an overt bleeding from duodenal varices was treated using sclerotherapy and clipping. Pharmacological therapy with vitamin K, high-dose proton pump inhibitor, octreotide and ceftriaxone was initiated. Despite mass transfusion and intubation, the patient could not be stabilized adequately and was transferred to the tertiary referral center the same day. At arrival, hemoglobin was at $8.4 \mathrm{~g} / \mathrm{dl}$, blood pressure 96/61 $\mathrm{mm} \mathrm{Hg}$ and the Model for End-Stage Liver Disease (MELD) score 21. The actively bleeding esophageal varices were immediately treated by band ligation. However, bleeding control was not sufficient and the patient underwent implantation of an emergency TIPS the following day. Additionally, because of continued bleeding, the duodenal varices were treated by histoacryl injection and the esophageal varices were compressed by implantation of a SX-ELLA Stent Danis. At this point, hemostasis was finally achieved and the stent could be removed without difficulty after a 5-day bleeding-free interval.

However, the course had been complicated by ongoing liver failure with hepatic encephalopathy, acute respiratory distress syndrome and acute anuric renal failure. Eleven days after the initial bleeding episode, recurrence of diffuse bleeding in the gastrointestinal tract was observed. The MELD score had increased to 29 at that time. Again, an esophagus stent was placed with successful local hemostasis as seen endoscopically. Owing to massive coagulopathy, however, there was an ongoing diffuse bleeding and the patient died 1 day later of multi-organ failure.

Case 2

Acute and unexpected onset of nausea and hematemesis in a 68-year-old patient led to admission to the emergency room of a peripheral hospital. At presentation, the patient was responsive, with pale complexion, blood pressure being 100/80 $\mathrm{mm} \mathrm{Hg}$, heart rate 100/min and hemoglobin level $10.2 \mathrm{~g} / \mathrm{l}$. He had a known history of alcohol abuse, liver cirrhosis (actual MELD score 11), past hepatitis B infection and has been treated with ibuprofen the last 2 days due to painful knees. Upon emergency endoscopy, an active esophageal variceal bleeding was revealed (fig. 3a). Attempts to control bleeding with rubber band ligation were not successful. The usual pharmacotherapy including vitamin $\mathrm{K}$, high-dose proton pump inhibitor, octreotide and ceftriaxone were immediately administered. While the patient's hemoglobin level dropped to $4.4 \mathrm{~g} / \mathrm{l}$, mass transfusion was initiated and as a rescue therapy, a SX-ELLA Stent Danis was deployed in the esophagus under endoscopic control, which led the hemorrhage to cease (fig. $3 \mathrm{~b}$ ). Under stable cardiocirculatory conditions and spontaneous respiration, the patient was then transferred to the secondary referral center. Subsequently, the stent was removed endoscopically and the patient underwent definitive therapy in terms of six-fold variceal band ligation on the day of transfer. Apart from an episode of 
Fierz et al.: Treatment of Esophageal Variceal Hemorrhage with Self-Expanding Metal

Stents as a Rescue Maneuver in a Swiss Multicentric Cohort

tachycardic atrial fibrillation, which was electrically converted back to sinus rhythm, the course of recovery was uneventful and the patient was dismissed from the hospital after 8 days. Today, 2 years later, the patient is in good health.

\section{Discussion}

The use of SEMS in acute esophageal hemorrhage is a new treatment modality to control initial bleeding. In $10-20 \%$ of patients, standard therapy combining pharmacological with endoscopic measures fails to stop initial hemorrhage [3], which points out the need for further treatment approaches. Studies up to now have reported success rates from 77 to $100 \%$ in initial control of hemorrhage using SEMS [13-16]. In the present case series, insertion of the stent led to immediate bleeding control in 89\% (8/9) of patients. In all of these 8 cases no re-bleeding was observed subsequently while the stent remained in situ. Therefore, in general the efficacy of this method seems not to be inferior to traditional balloon tamponade, with success rates for short-term hemostasis from 50 to 90\% [7-9]. We did not observe any stent-related complications in our patients.

According to the Baveno $\mathrm{V}$ consensus guidelines [11], treatment success of an acute bleeding episode is measured within a time frame of 5 days. Thereby, a hepatic venous pressure gradient $>20 \mathrm{~mm} \mathrm{Hg}$, Child-Pugh $\mathrm{C}$ and active bleeding at endoscopy qualify as predictors for 5-day treatment failure. All of the 9 cases presenting with active bleeding and 7/9 cases being classified as Child-Pugh C indicated a high-risk patient collective in the present study. 5-day treatment failure in 56\% (5/9) cases is therefore not surprising; 3 out of these 5 cases died before reaching eligibility for definitive therapy such as TIPS placement. In the other 2 of these 5 cases, the patients had already been treated with salvage TIPS at their first bleeding episode but did then not survive the second bleeding episode (cases $1 \mathrm{~b}$ and $3 \mathrm{~b}$ ). In turn, case 4 was treated by elective TIPS after hemorrhage had been controlled by the SEMS and survived the 42-day period. Case 2 received band ligation as a definitive therapy after stent removal and is still alive today.

6-week mortality - as any death within 6 weeks must be considered a bleeding-related [11] - sums up to 77\% (7/9 patients). Other studies on the use of SEMS have reported 6-week mortality rates from 30 to 50\% [14-16]. These figures are significantly higher than a general 6-week mortality rate of $15-20 \%$ using standard techniques [3-5]. This impressive difference implies a selection bias of these collectives with most severe underlying liver diseases. Therefore it is important to keep in mind that in all studies so far, SEMS have virtually only been used in treatment-refractory variceal hemorrhage meaning above-average risk for treatment failure. Case $1 \mathrm{a}+\mathrm{b}$ described above is exemplary for such a high-risk setting. The patient had end-stage liver disease with poor prognosis already at hospital admission. She was treated at the tertiary referral center with all therapeutic options available. The SEMS was used as ultima ratio and indeed helped the patient to survive another 10 days, not preventing ongoing liver disease and finally death due to multi-organ failure. On the other hand, case 2 points out the ability of the stent to serve as an elegant bridging measure to definitive therapy. Here we have a patient with moderately advanced liver disease, life-threatened by an unexpected bleeding episode. Upon presentation at a peripheral hospital, he was successfully treated with a SEMS and then transferred to a secondary referral center for stabilization and definitive therapy. One might further consider the usage of the SX-ELLA Stent Danis in the setting of any ambulance. The SEMS device is made to be inserted without endoscopy, which in fact has been described in 1 case by Wright et al. [15]. This approach may save lives in the pre-hospital phase. Anyhow, at the hospital gastroscopy 
Fierz et al.: Treatment of Esophageal Variceal Hemorrhage with Self-Expanding Metal Stents as a Rescue Maneuver in a Swiss Multicentric Cohort

is inevitable in any case because gastric varices are not adequately treated by SEMS. In these situations a combination with a Linton tube may be a feasible and reasonable option, as we did once (case 5 in table 1).

In conclusion, the use of SEMS is an effective and safe way of controlling initial hemorrhage from esophageal varices and might replace balloon tamponade in the future as a bridging measure to definitive therapy, especially as the stent may remain in the esophagus for up to 7 days. Mortality, however, remains high mainly due to underlying advanced liver disease in the patient collective treated.

\section{References}

1 Banares R, Albillos A, Rincón D, Alonso S, González M, Ruiz-del-Arbol L, Salcedo M, Molinero LM: Endoscopic treatment versus endoscopic plus pharmacologic treatment for acute variceal bleeding: a meta-analysis. Hepatology 2002;35:609-615.

2 Garcia-Pagán JC, Pascoli MD, Caca K, Laleman W, Bureau C, Appenrodt B, Luca A, Zipprich A, Abraldes JG, Nevens F, Vinel JP, Sauerbruch T, Bosch J: Early use of TIPS in patients with cirrhosis and variceal bleeding. N Engl J Med 2010;362:2370-2379.

-3 D’Amico G, De Franchis R; Cooperative Study Group: Upper digestive bleeding in cirrhosis. Post-therapeutic outcome and prognostic indicators. Hepatology 2003;38:599-612.

4 Stokkeland K, Brandt L, Ekbom A, Hultcrantz R: Improved prognosis for patients hospitalized with esophageal varices in Sweden 1969-2002. Hepatology 2006;43:500-505.

-5 Carbonell N, Pauwels A, Serfaty L, Fourdan O, Lévy VG, Poupon R: Improved survival after variceal bleeding in patients with cirrhosis over the past two decades. Hepatology 2004;40:652-659.

-6 Augustin S, Altamirano J, González A, Dot J, Abu-Suboh M, Armengol JR, Azpiroz F, Esteban R, Guardia J, Genescà J: Effectiveness of combined pharmacologic and ligation therapy in high-risk patients with acute esophageal variceal bleeding. Am J Gastroenterol 2011;106:1787-1795.

-7 Panés J, Terés J, Bosch J, Rodés J: Efficacy of balloon tamponade in treatment of bleeding gastric and esophageal varices. Results in 151 consecutive episodes. Dig Dis Sci 1988;33:454-459.

-8 Jaramillo JL, de la Mata M, Miño G, Costán G, Gómez-Camacho F: Somatostatin versus Sengstaken balloon tamponade for primary haemostasia of bleeding esophageal varices. A randomized pilot study. J Hepatol 1991;12:100-105.

$>9$ D’Amico G, Pagliaro L, Bosch J: The treatment of portal hypertension: a meta-analytic review. Hepatology 1995;22:332-354.

10 Sorbi D, Gostout CJ, Peura D, Johnson D, Lanza F, Foutch PG, Schleck CD, Zinsmeister AR: An assessment of the management of acute bleeding varices: a multicenter prospective member-based study. Am J Gastroenterol 2003;98:2424-2434.

11 De Franchis R; Baveno V Faculty: Revising consensus in portal hypertension: report of the Baveno V consensus workshop on methodology of diagnosis and therapy in portal hypertension. J Hepatol 2010;53: 762-768.

12 Dormann A, Meisner S, Verin N, Wenk Lang A: Self-expanding metal stents for gastroduodenal malignancies: systematic review of their clinical effectiveness. Endoscopy 2004;36:543-550.

13 Hubmann R, Bodlaj G, Czompo M, Benkö L, Pichler P, Al-Kathib S, Kiblböck P, Shamyieh A, Biesenbach GI: The use of self-expanding metal stents to treat acute esophageal variceal bleeding. Endoscopy 2006;38: 896-901.

-14 Zehetner J, Shamiyeh A, Wayand W, Hubmann R: Results of a new method to stop acute bleeding from esophageal varices: implantation of a self-expanding stent. Surg Endosc 2008;22:2149-2152.

15 Wright G, Lewis H, Hogan B, Burroughs A, Patch D, O'Beirne JA: self-expanding metal stent for complicated variceal hemorrhage: experience at a single center. Gastrointest Endosc 2010;71:71-78.

16 Dechêne A, El Fouly AH, Bechmann LP, Jochum C, Saner FH, Gerken G, Canbay A: Acute management of refractory variceal bleeding in liver cirrhosis by self-expanding metal stents. Digestion 2012;85:185-191. 


\begin{tabular}{|c|c|c|}
\hline \multirow{2}{*}{$\begin{array}{r}\text { Case Reports in } \\
\text { Gastroenterology }\end{array}$} & \multicolumn{2}{|c|}{ Case Rep Gastroenterol 2013;7:97-105 } \\
\hline & DOI: $\underline{10.1159 / 000350192}$ & $\begin{array}{l}\text { (C) } 2013 \text { S. Karger AG, Basel } \\
\text { www.karger.com/crg }\end{array}$ \\
\hline
\end{tabular}

Table 1. Baseline patient characteristics and treatment parameters

\begin{tabular}{|c|c|c|c|c|c|c|c|c|c|}
\hline & \multicolumn{9}{|l|}{ Case No. } \\
\hline & $1 \mathrm{a}$ & $1 b$ & 2 & $3 a$ & $3 \mathrm{~b}$ & 4 & 5 & 6 & 7 \\
\hline \multicolumn{10}{|l|}{ Patient data } \\
\hline Age & 56 & 56 & 68 & 65 & 65 & 56 & 64 & 41 & 48 \\
\hline & female & female & male & male & male & male & male & male & female \\
\hline Liver disease 1 & ethanol & ethanol & ethanol & ethanol & ethanol & $\mathrm{HBV}$ & ethanol & $\begin{array}{l}\mathrm{HBV} / \\
\mathrm{HDV}\end{array}$ & $\mathrm{HCV}$ \\
\hline Liver disease 2 & - & - & HBV & - & - & - & - & ethanol & ethanol \\
\hline Child & $\mathrm{C}$ & $\mathrm{C}$ & B & $\mathrm{C}$ & $\mathrm{C}$ & $\mathrm{B}$ & $\mathrm{C}$ & $\mathrm{C}$ & $\mathrm{C}$ \\
\hline MELD & 21 & 29 & 11 & 36 & 25 & 31 & 36 & 37 & 13 \\
\hline Creatinine (mg/dl) & 0.7 & 1.0 & 1.0 & 3.0 & 1.3 & 3.4 & 3.8 & 2.8 & 1.0 \\
\hline \multicolumn{10}{|l|}{ Present bleeding episode } \\
\hline $\mathrm{Hb}(\mathrm{g} / \mathrm{dl})$ before stenting & 8.4 & 7.9 & 10.2 & 6.7 & 7.7 & 6.6 & 7.5 & 7.3 & 8.0 \\
\hline $\mathrm{Hb}(\mathrm{g} / \mathrm{dl})$ minimum within 5 days after stenting & 6.4 & 6.1 & 4.4 & 6.0 & 6.5 & 6.6 & 7.1 & 7.1 & 6.3 \\
\hline Platelet count (G/l) before stenting & 52,000 & 27,000 & 119,000 & 38,000 & 58,000 & 162,000 & 49,000 & 54,000 & 59,000 \\
\hline $\begin{array}{l}\text { Platelet count }(\mathrm{G} / \mathrm{l}) \text { minimum within } 5 \text { days after } \\
\text { stenting }\end{array}$ & 20,000 & 27,000 & 50,000 & 32,000 & 43,000 & 51,000 & 47,000 & 32,000 & 59,000 \\
\hline Different treatment approach prior to stenting & $\begin{array}{l}\text { sclero- } \\
\text { therapy, } \\
\text { band } \\
\text { ligation }\end{array}$ & - & $\begin{array}{l}\text { band } \\
\text { ligation }\end{array}$ & $\begin{array}{l}\text { band } \\
\text { ligation, } \\
\text { sclero- } \\
\text { therapy }\end{array}$ & - & - & $\begin{array}{l}\text { band } \\
\text { ligation }\end{array}$ & ligation & $\begin{array}{l}\text { band } \\
\text { ligation }\end{array}$ \\
\hline Active bleeding at endoscopy & yes & yes & yes & yes & yes & yes & yes & yes & yes \\
\hline Type of varices bleeding & $\begin{array}{l}\text { esoph- } \\
\text { ageal, } \\
\text { duodenal }\end{array}$ & $\begin{array}{l}\text { esoph- } \\
\text { ageal }\end{array}$ & $\begin{array}{l}\text { esoph- } \\
\text { ageal }\end{array}$ & $\begin{array}{l}\text { esoph- } \\
\text { ageal }\end{array}$ & $\begin{array}{l}\text { esoph- } \\
\text { ageal }\end{array}$ & $\begin{array}{l}\text { esoph- } \\
\text { ageal }\end{array}$ & $\begin{array}{l}\text { esoph- } \\
\text { ageal, } \\
\text { gastric }\end{array}$ & $\begin{array}{l}\text { esoph- } \\
\text { ageal }\end{array}$ & $\begin{array}{l}\text { esoph- } \\
\text { ageal }\end{array}$ \\
\hline Successful deployment of stent & yes & yes & yes & no & yes & yes & yes & - & yes \\
\hline Immediate bleeding control (at time of endoscopy) & yes & yes & yes & no & yes & yes & yes & yes & yes \\
\hline Stenting period & $5 \mathrm{~d}$ & $12 \mathrm{~h}$ & $24 \mathrm{~h}$ & - & $12 \mathrm{~h}$ & $3 d$ & $20 \mathrm{~h}$ & $30 \mathrm{~h}$ & $24 \mathrm{~h}$ \\
\hline Rebleeding with stent in situ & no & no & no & - & no & no & no & no & no \\
\hline Final treatment & $\begin{array}{l}\text { salvage } \\
\text { TIPS }\end{array}$ & de- & band & $\begin{array}{l}\text { salvage } \\
\text { TIPS }\end{array}$ & de- & TIPS & de- & de- & de- \\
\hline 5-day follow-up & $\begin{array}{l}\text { TIPS } \\
\text { alive }\end{array}$ & $\begin{array}{l}\text { ceased } \\
-\end{array}$ & $\begin{array}{l}\text { ligation } \\
\text { alive }\end{array}$ & $\begin{array}{l}\text { TIPS } \\
\text { alive }\end{array}$ & $\begin{array}{l}\text { ceased } \\
-\end{array}$ & alive & $\begin{array}{l}\text { ceased } \\
-\end{array}$ & $\begin{array}{l}\text { ceased } \\
-\end{array}$ & $\begin{array}{l}\text { ceased } \\
-\end{array}$ \\
\hline 42-day follow-up & deceased & $1-$ & alive & deceased & $1-$ & alive & - & - & - \\
\hline \multicolumn{10}{|l|}{ Placement procedure } \\
\hline Placement with endoscopic assistance? & yes & yes & yes & yes & yes & yes & yes & yes & yes \\
\hline Stent dislocation to stomach? & no & no & no & yes & no & yes & no & no & no \\
\hline $\begin{array}{l}\text { Stent-associated bleeding, perforation or airway } \\
\text { compression? }\end{array}$ & no & no & no & no & no & no & no & no & no \\
\hline
\end{tabular}




\section{Case Reports in \\ Gastroenterology}

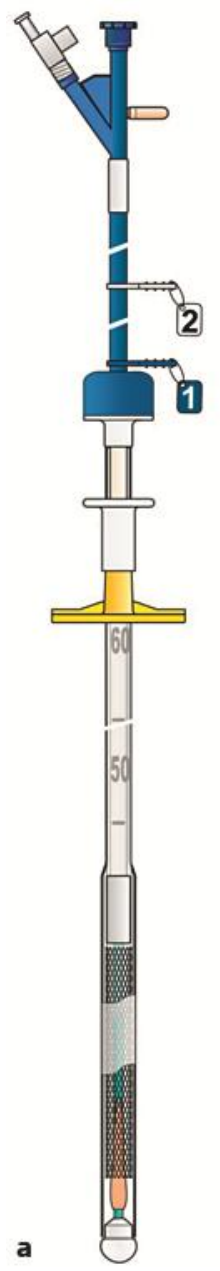

Fierz et al.: Treatment of Esophageal Variceal Hemorrhage with Self-Expanding Metal

Stents as a Rescue Maneuver in a Swiss Multicentric Cohort

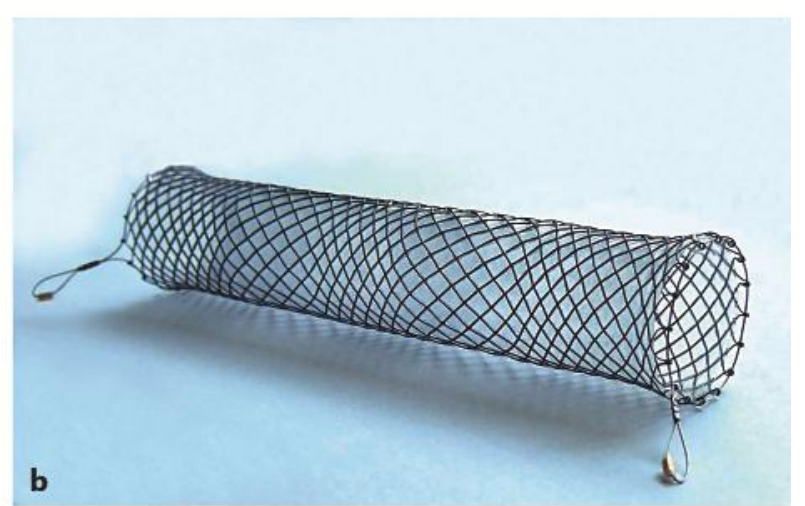

Fig. 1. a Schematic view of the delivery system of the SX-ELLA Stent Danis preloaded with the compressed stent. b Photograph of the deployed stent with a diameter of $25 \mathrm{~mm}$ and a length of $135 \mathrm{~mm}$. The stent is made of nitinol and fully covered by a plastic membrane. Courtesy of ELLA-CS, Hradec-Kralove, Czech Republic. 


\begin{tabular}{ll|l} 
Case Reports in & \multicolumn{2}{l}{} \\
\cline { 2 - 3 } Gastroenterology & Case Rep Gastroenterol 2013;7:97-105 \\
\cline { 2 - 3 } & DOI: $\frac{10.1159 / 000350192}{}$ & $\begin{array}{l}\text { C 2013 S. Karger AG, Basel } \\
\text { www.karger.com/crg }\end{array}$ \\
\cline { 2 - 3 } & Fierz et al: Treatment of Esophageal Variceal Hemorrhage with Self-Expanding Metal
\end{tabular}

Fierz et al.: Treatment of Esophageal Variceal Hemorrhage with Self-Expanding Metal Stents as a Rescue Maneuver in a Swiss Multicentric Cohort

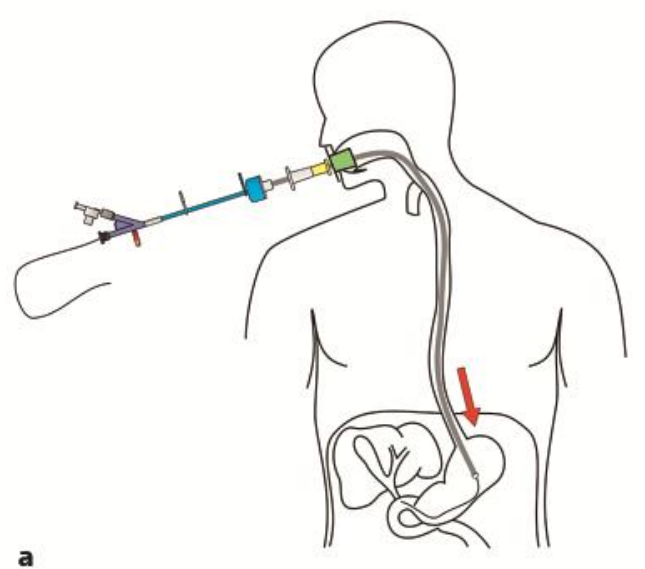

a

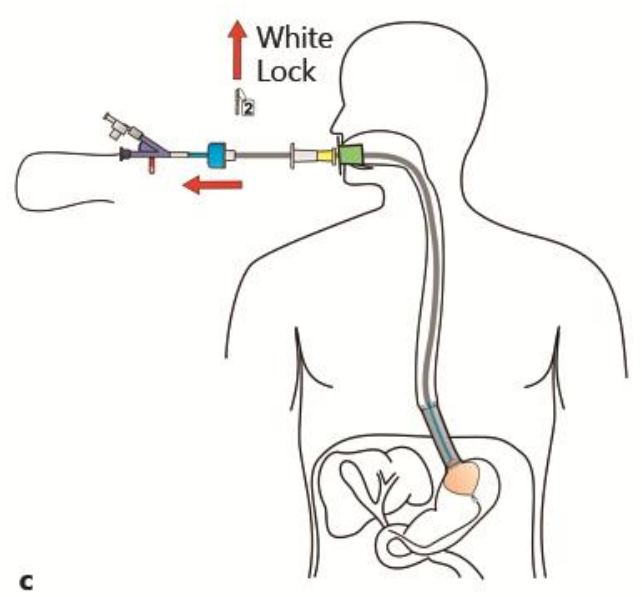

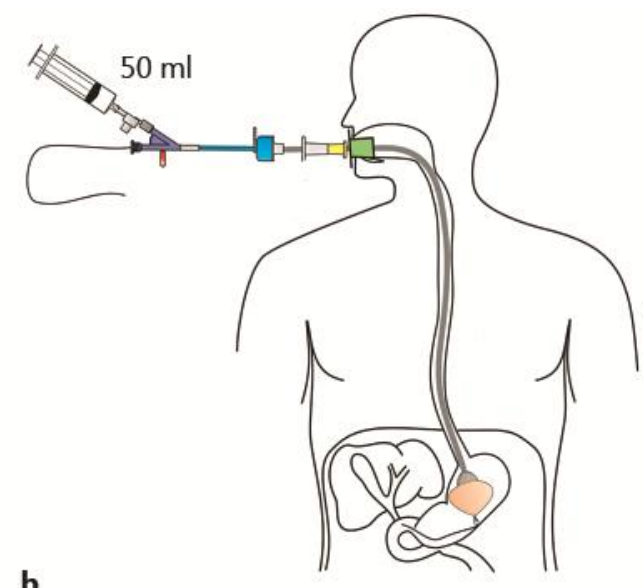

b

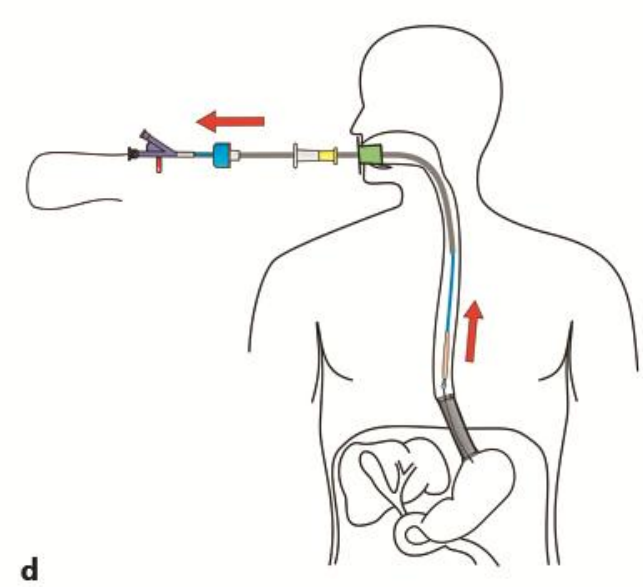

Fig. 2. a If stent placement is assisted endoscopically, the guide wire is inserted through the working channel of the endoscope. Otherwise, the delivery system can be inserted directly into the esophagus. b For fixation of the delivery system to the stomach, the balloon is inflated and pulled back against the cardia. c Stent deployment is achieved by removing the lock and pulling back the sheath handle. $\mathbf{d}$ The delivery system is removed, leaving behind the deployed stent in the distal esophagus. The stent can be left in the esophagus for up to 7 days. Courtesy of ELLA-CS, Hradec-Kralove, Czech Republic. 


\begin{tabular}{ll|l} 
Case Reports in & \multicolumn{2}{l}{ Case Rep Gastroenterol 2013;7:97-105 } \\
\cline { 2 - 3 } Gastroenterology & DOI: $10.1159 / 000350192$ & $\begin{array}{l}\text { ○ 2013 S. Karger AG, Basel } \\
\text { www.karger.com/crg }\end{array}$ \\
\cline { 2 - 3 } & Fierz et al.: Treatment of Esophageal Variceal Hemorrhage with Self-Expanding Metal
\end{tabular}

Stents as a Rescue Maneuver in a Swiss Multicentric Cohort
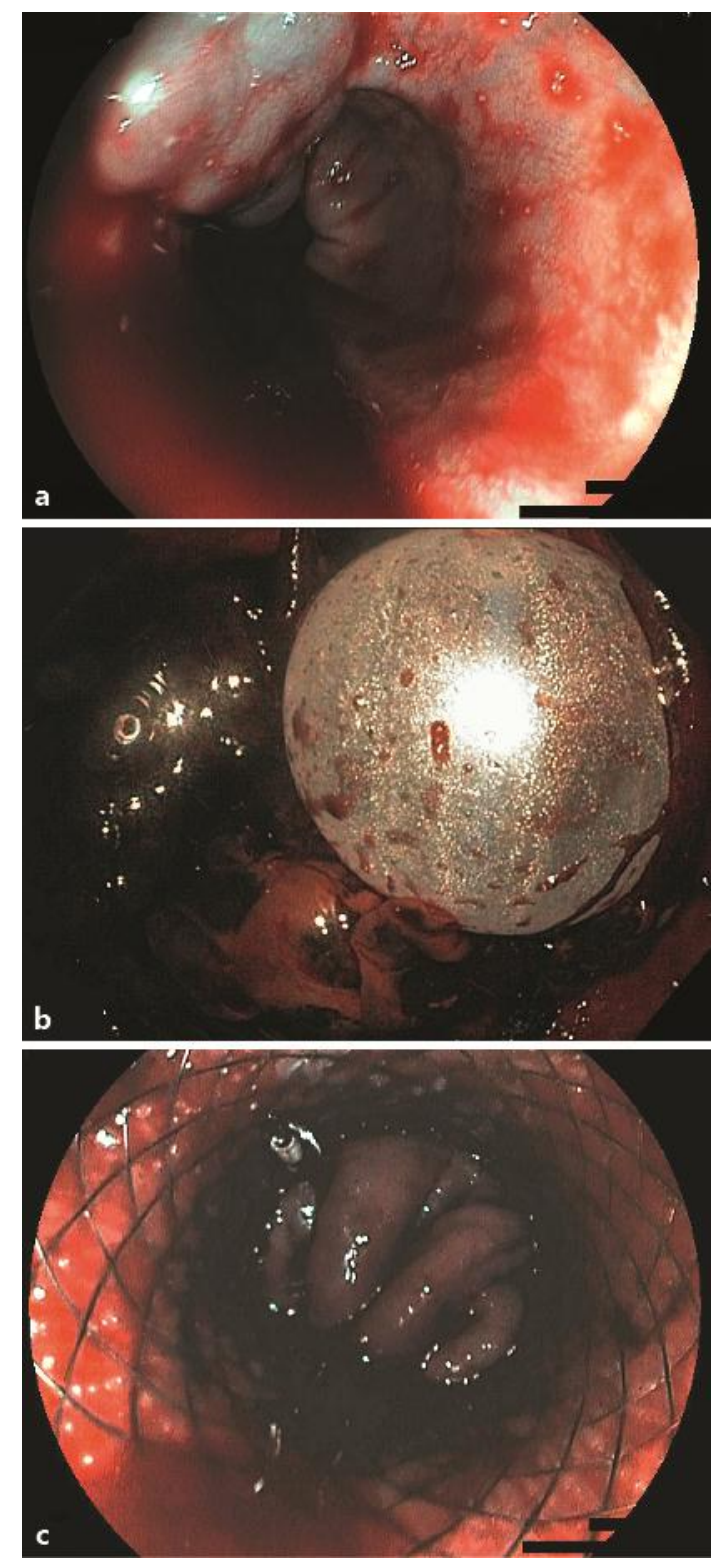

Fig. 3. a Endoscopic image of active hemorrhage of esophageal varices in Child B liver cirrhosis. b Retrograde image of the inflated balloon of the stent delivery system at the cardia. $\mathbf{c}$ The covered stent in the distal esophagus with compression of the varices leading to hemostasis. 